\title{
HUBUNGAN SUMBER INFORMASI DENGAN PERILAKU PERSONAL HYGIENE PADA REMAJA PUTRI SAAT MENSTRUASI
}

\author{
The Correlation Between Information Sources with Personal Hygiene Behaviors on \\ Teenage Girl During Menstruation
}

\author{
AuliaAnjan', Dwi Susanti² \\ ${ }^{1}$ Mahasiswa Keperawatan, Fakultas Kesehatan Universitas Jenderal Achmad Yani, Yogyakarta, Indonesia \\ ${ }^{2}$ Prodi Keperawatan, Fakultas Kesehatan Universitas Jenderal Achmad Yani, Yogyakarta, Indonesia \\ Korespondensi: soesanti_2@yahoo.com
}

\begin{abstract}
ABSTRAK
Perubahan seks primer pada remaja ditandai dengan haid (menarche) yang pertama dan akan diikuti oleh perubahan seks sekunder. Pada saat haid pembuluh darah dalam rahim akan mudah terinfeksi dan kuman akan mudah masuk, sehingga dibutuhkan kesehatan reproduksi dengan cara menjaga perilaku personal hygiene saat menstruasi. Penelitian ini bertujuan untuk mengetahui hubungan sumber informasi terhadap perilaku personal hygiene saat mensturasi remaja putri SMP N 1 Gamping Sleman Yogyakarta. Penelitian ini merupakan penelitian kuantitatif non eksperimental, tehnik pengambilan sampel menggunakan stratified random sampling dengan jumlah sampel 62 responden, data diambil menggunakan kuesioner. Analisa data yang digunakan adalah analisis univariat dan analisis bivariat menggunakan Chi Square. Sumber informasi yang didapatkan responden dari berbagai macam sumber antara lain, dari orang tua $69,4 \%$, guru $43,5 \%$, media masa $46,8 \%$, saudara perempuan $27,4 \%$, teman sebaya $22,6 \%$ dan dari tenaga kesehatan $79 \%$. Perilaku personal hygiene saat menstruasi dalam kategori positif $62,9 \%$. Nilai $p$-value untuk sumber informasi dari orangtua terhadap perilaku personal hygiene saat menstruasi adalah 0,000 , guru 0,001 , media masa 0,000 , saudara 0,000 , teman sebaya 0,007 dan tenaga kesehatan $0,000<0,05$. Terdapat hubungan antara berbagai sumber informasi terhadap perilaku personal hygiene saat menstruasi remaja putri SMP N 1 Gamping Sleman Yogyakarta.
\end{abstract}

Kata Kunci: sumber informasi, perilaku personal hygiene, menstruasi

\section{ABSTRACT}

Primary sex relocation in adolescents is characterized by the first menstruation (menarche) and will be followed by secondary sex changes. At the time of menstruation the blood vessels in the uterus will be easily infected and germs will easily enter, so that reproductive health is needed in women by maintaining personal hygiene behavior when menstruating. This study aims to determine the relationship of sources of information on personal hygiene behavior when draining girls from SMP N 1 Gamping Sleman Yogyakarta. This research is a non-experimental quantitative study. The sampling technique uses stratified random sampling with a sample of 62 respondents, data taken using questionnaires. Analysis of the data used is univariate analysis and bivariate analysis using Chi Squere. Sources of information obtained by respondents from a variety of sources include, among others, $69.4 \%$ parents, teachers $43.5 \%$, mass media $46.8 \%$, sisters $27.4 \%$, peers $22.6 \%$ and $79 \%$ of health workers. Personal hygiene behavior when menstruating in the positive category was $62.9 \%$. The p-value of the chi-square test for sources of information from parents on personal hygiene behavior when menstruating was 0,000, teachers 0,001, mass media 0,000, relatives 0,000, peers 0,007 and health workers 0,000<0,05. There is a relationship between various sources of information on personal hygiene behavior when menstruating young women in SMP N 1 Gamping

Keywords: information sources, behavior personal hygiene, menstruation 
AuliaAnjan : Hubungan Sumber Informasi Dengan Perilaku Personal Hygiene Pada Remaja Putri Saat Menstruasi

\section{PENDAHULUAN}

Menurut Word Health Organization (WHO), usia remaja digolongkan sekitar usia 10-19 tahun (WHO, 2018). Sedangkan menurut Kementrian Kesehatan RI mendefinisikan remaja yaitu sekitar usia 1018 tahun (Kemenkes RI, 2017). Hasil Sensus Penduduk yang dilakukan di Kota Yogyakarta pada tahun 2015 dengan proporsi remaja usia $15-19$ sebanyak 7,41\% untuk laki-laki dan 7,01\% untuk perempuan. Remaja akan melalui banyak peristiwa dalam tahap perkembangan dan pertumbuhan. Salah satunya perubahan fisik, pada perubahan fisik terjadi perubahan tanda-tanda seks primer dan tanda-tanda seks sekunder. Perubahan seks primer yang terjadi pada remaja perempuan yaitu ditandai dengan terjadinya haid (menarche) yang pertama kemudian akan diikuti oleh perubahan seks sekunder yaitu pinggul melebar, pertumbuhan rahim dan vagina, tumbuh rambut disekitar kemaluan dan vagina dan payudara membesar, sebagai tanda bahwa organ reproduksi mulai berfungsi (Irianto, 2015).

Pada saat menstruasi remaja putri rentan terkena infeksi organ reproduksi. Hal tersebut akan terjadi apabila berperilaku tidak merawat kebersihan diri terutama saat mensturasi (Andira, 2010). Selain itu, dampak lain yang bisa terjadi apabila perilaku personal Hygiene jelek adalah kanker serviks dan kesehatan reproduksi lainnya (Nugroho, dkk, 2015). Akibat dari keputihan sangat fatal bila lambat ditangani, dan bisa mengakibatkan kemandulan dan hamil diluar kandungan dikarenakan terjadi penyumbatan pada saluran tuba (Allaily, 2016).

Melihat dari berbagai dampak negatif ketika personal hygiene buruk saat menstruasi, maka remaja putri sangat perlu diberikan informasi yang baik dan positif melalui orang tua, teman sebaya dan guru sekolah tentang bagaimana menjaga kerbersihan saat mensturasi. Namun masyarakat menganggap kesehatan reproduksi masih tabu untuk dibicarakan oleh remaja. Hal tersebut dapat membatasi komunikasi antara orangtua dan remaja tentang menstrual hygiene. Akibatnya, remaja kurang mengerti, kurang memahami dan kadang-kadang mengambil keputusan yang salah mengenai kesehatan reproduksi (Djannah \& Gustina, 2015).

Berdasarkan studi pendahuluan yang dilakukan dengan cara mewawancarai 10 siswi di SMP N 1 Gamping pada tanggal 4 Januari 2019 didapatkan 6 dari 10 siswi memiliki perilaku personal hygiene yang salah antara lain, menggunakan celana dalam yang ketat saat menstruasi, menggunakan sabun mandi untuk membersihkan daerah kewanitaan, tidak mengganti pembalut ketika buang air kecil, tidak mengganti pembalut saat ada gumpalan darah. Sumber informasi yang diperoleh oleh siswi mengenai perilaku personal hygiene saat menstruasi banyak didapatkan dari ibu.

\section{TUJUAN PENELITIAN}

Tujuan dari penelitian ini adalah untuk mengetahui hubungan antara sumber informasi dengan perilaku personal hygiene saat menstruasi pada siswi di SMP N 1 Gamping Sleman Yogyakarta.

\section{METODE PENELITIAN}

Desain

Desain yang digunakan adalah desain deskriptif korelasional dengan menggunakan metode cross sectional (Notoatmodjo, S. (2014).

\section{Populasi dan Sampel}

Populasi dalam penelitian ini adalah siswi SMP N 1 Gamping yang sudah mengalami menstrusi. Teknik sampling yang digunakan adalah stratified random sampling dengan jumlah responden 62 siswi.

\section{Lokasi dan Waktu Penelitian}

Lokasi penelitian ini dilaksanakan di SMP N 1 Gamping Kabupaten Sleman Yogyakarta. Pengambilan data dilaksanakan pada bulan Maret sampai dengan bulan Juli tahun 2019. Variabel dalam penelitian ini adalah variabel sumber informasi dan variabel perilaku personal hygiene saat menstruasi. 
AuliaAnjan : Hubungan Sumber Informasi Dengan Perilaku Personal Hygiene Pada Remaja Putri Saat Menstruasi

\section{Instrumen Penelitian}

Alat pengumpulan data yang digunakan adalah kuesioner sumber informasi dan variabel perilaku personal hygiene saat menstruasi.

\section{Analisis Data}

Data yang sudah terkumpul kemudian dilakukan editing, coding, entry dan tabulating. Analisis data yang digunakan yaitu analisis univariat dan bivariat. Analisis bivariatnya menggunakan analisis chi-square.

\section{HASIL PENELITIAN}

Karakteristik Responden

Uraian karakteristik responden disajikan dalam bentuk tabel sebagai berikut:

Tabel. 1

Distribusi Frekuensi Karakteristik Responden $(\mathrm{n}=62)$

\begin{tabular}{ccc}
\hline $\begin{array}{c}\text { Karakteristik } \\
\text { Responden }\end{array}$ & $\mathrm{n}$ & $\%$ \\
\hline Usia & & \\
10-13 tahun & 27 & 43,5 \\
14-16 tahun & 35 & 56,5 \\
\hline Usia pertama haid & & \\
10-13 tahun & 61 & 98,4 \\
14-15 tahun & 1 & 1,6 \\
\hline Memiliki kakak & & \\
perempuan & & \\
Iya & 25 & 40,3 \\
Tidak & 37 & 59,7 \\
\hline Menggunakan & & \\
gadged & 60 & 96,8 \\
Iya & 2 & 3,2 \\
Tidak & 62 & 100 \\
\hline Total &
\end{tabular}

Karateristik responden menurut usia sebagian besar dalam rentang usia 14-16 tahun sebanyak 35 siswa $(56,5 \%)$ dan dan karateristik responden berdasarkan usia pertama kali haid mayoritas pada usia 10 13 tahun sebanyak 61 responden $(98,4 \%)$, tidak memiliki kakak perempuan sebanyak 37 responden $(59,7 \%)$, mayoritas menggunan gadged sebanyak 60 responden (96,8\%). Distribusi karakteristik responden dapat dilihat pada Tabel 1.

\section{Sumber Informasi}

Sumber informasi remaja tentang personal hygiene saat menstruasi dapat dilihat pada Tabel 2 .

Tabel. 2

Distribusi Frekuensi Responden

Berdasarkan Pengalaman Sumber Informasi Tentang Personal Hygiene

$$
(\mathrm{n}=62)
$$

\begin{tabular}{ccc}
\hline $\begin{array}{c}\text { Pengalaman } \\
\text { Sumber Informasi }\end{array}$ & $\mathrm{n}$ & $\%$ \\
\hline Orangtua & & \\
Iya & 43 & 69,4 \\
Tidak & 19 & 30,6 \\
\hline Guru & & \\
Iya & 27 & 43,5 \\
Tidak & 35 & 56,5 \\
\hline Media masa & & \\
Iya & 29 & 53,2 \\
Tidak & 33 & 46,8 \\
\hline Saudara & & \\
perempuan & 17 & 27,4 \\
Iya & 45 & 72,6 \\
Tidak & & \\
Teman sebaya & 14 & 22,6 \\
Iya & 48 & 77,4 \\
Tidak & & \\
\hline Tenaga kesehatan & 49 & 79,0 \\
Iya & 13 & 21,0 \\
Tidak & 62 & 100 \\
\hline Total & &
\end{tabular}

Berdasarkan Tabel 2 diketahui pengalaman sumber informasi tentang perilaku personal hygiene saat menstruasi mayoritas mendapatkan informasi dari orangtua $(69,4 \%)$, tidak mendapatkan informasi dari guru (56,5\%), tidak mendapatkan informasi dari media masa $(53,2 \%)$, mayoritas tidak mendapatkan informasi dari saudara perempuan $(72,6 \%)$ dan teman sebaya $(77,4 \%)$, sedangkan sumber informasi dari tenaga kesehatan mayoritas mendapatkan informasi $(79 \%)$.

Perilaku Personal Hygiene Saat Menstruasi

Perilaku personal hygiene saat mentruasi dapat dilihat pada Tabel 3. 
AuliaAnjan : Hubungan Sumber Informasi Dengan Perilaku Personal Hygiene Pada Remaja Putri Saat Menstruasi

Tabel. 3

Distribusi Frekuensi Responden Berdasarkan Perilaku Personal Hygiene Saat Menstruasi $(\mathrm{n}=62)$

\begin{tabular}{ccc}
\hline $\begin{array}{c}\text { Perilaku Personal } \\
\text { Hygiene }\end{array}$ & $\mathrm{n}$ & $\%$ \\
\hline Positif & 39 & 62,9 \\
Negatif & 23 & 37,1 \\
\hline Total & 62 & 100 \\
\hline
\end{tabular}

Berdasarkan Tabel 3 dapat diketahui perilaku remaja putri tentang perilaku personal hygiene saat mensturasi sebagian besar remaja putri memiliki perilaku positif sebanyak 39 responden $(62,9 \%)$.

\section{Tabel 4}

Uji Tabulasi Silang Hubungan Sumber Informasi Dari Orangtua Dengan Perilaku Personal Hygiene Saat Menstruasi Pada Remaja Putri $(\mathrm{n}=62)$

\begin{tabular}{|c|c|c|c|c|c|c|c|}
\hline \multirow{3}{*}{$\begin{array}{l}\text { Sumber } \\
\text { informasi }\end{array}$} & \multicolumn{7}{|c|}{ Perilaku Personal Hygiene } \\
\hline & \multicolumn{2}{|c|}{ Positif } & \multicolumn{2}{|c|}{ Negatif } & \multicolumn{2}{|c|}{ Total } & \multirow[t]{2}{*}{ p-Value } \\
\hline & (n) & $(\%)$ & (n) & $(\%)$ & (n) & $(\%)$ & \\
\hline Orangtua & 34 & 54,8 & 9 & 14,5 & 43 & 69,4 & 0,00 \\
\hline $\begin{array}{c}\text { lya } \\
\text { Tidak }\end{array}$ & 5 & 8,1 & 14 & 22,6 & 19 & 30,6 & 0 \\
\hline \multicolumn{8}{|l|}{ Guru } \\
\hline Iya & 23 & 37,1 & 4 & 6,4 & 27 & 43,5 & 0,00 \\
\hline Tidak & 16 & 25,8 & 19 & 30,6 & 35 & 56,5 & 1 \\
\hline \multicolumn{8}{|l|}{ Media } \\
\hline Iya & 28 & 45,2 & 1 & 1,6 & 29 & 46,8 & 0,00 \\
\hline Tidak & 11 & 17,7 & 22 & 35,5 & 33 & 53,2 & 0 \\
\hline \multicolumn{8}{|l|}{ Saudara } \\
\hline Iya & 17 & 27,4 & 0 & 0,0 & 17 & 27,4 & 0,00 \\
\hline Tidak & 22 & 35,5 & 23 & 37,1 & 45 & 72,6 & 0 \\
\hline \multicolumn{8}{|l|}{ Teman } \\
\hline Iya & 13 & 21,0 & 1 & 1,6 & 14 & 22,6 & 0,00 \\
\hline Tidak & 26 & 41,9 & 22 & 35,5 & 48 & 77,4 & 7 \\
\hline
\end{tabular}

Tenaga

kesehatan

\begin{tabular}{clllllll} 
Iya & 39 & 62,9 & 10 & 16,1 & 49 & 79,0 & 0,00 \\
Tidak & 0 & 0,0 & 13 & 21,0 & 13 & 21,0 & 0 \\
\hline Total & 39 & 62,9 & 23 & 37,1 & 62 & 100 & \\
\hline
\end{tabular}

Dari Tabel 4 diketahui hasil analisis hubungan sumber informasi dengan perilaku personal hygiene saat menstruasi antara lain: sumber informasi dari orangtua ( $p$ value $0,000<0,05)$, sumber informasi dari guru ( $p$ value $0,001<0,05$ ), sumber informasi dari media masa ( $p$ value $0,000<0,05)$, sumber informasi dari guru ( $p$ value $0,001<0,05$ ), sumber informasi dari saudara perempuan ( $p$ value $0,000<0,05)$, sumber informasi dari teman sebaya ( $p$ value $0,007<0,05$ ), sumber informasi dari tenaga kesehatan ( $p$ value $0,000<0,05)$.

\section{PEMBAHASAN \\ Sumber Informasi dari Orang Tua}

Berdasarkan hasil analisis terdapat hubungan antara sumber informasi dari orangtua terhadap perilaku personal hygiene saat menstruasi remaja putri SMP N 1 Gamping Sleman. Hasil penelitian ini sejalan dengan penelitian yang dilakukan oleh penelitian sebelumnya yang menunjukaan adanya hubungan sumber informasi dari ibu terhadap perilaku personal hygiene (Eswi, dkk, 2014). Didukung juga dengan penelitian yang dilakukan oleh penelitian sebelumnya yang menyatakan ada hubungan antara informasi dari orangtua (ibu) dengan peraktik kebersihan saat mensturasi (Suhasni \& Chandra, 2016). Peran keluarga terutama ibu dalam kesehatan adalah memberikan pengetahui pada putrinya tentant masalah kesehatan, melakukan perawatan dan mampu memanfaatkan pelayanan kesehatan yang ada. Pengetahuan yang dapat diberikan kepada remaja tentang menstruasi pertama berupa pengetahuan tentang proses terjadinya menstruasi secara biologis, dukungan emosional, dan dukungan psikologis. Keluarga, terutama ibu adalah sebagai lingkungan utama remaja memegang peranan penting dalam membentuk perilaku remaja (Tarwoto \& Wartonah, 2010).

\section{Sumber Informasi dari Guru}

Berdasarkan hasil analisis terdapat hubungan antara sumber informasi dari guru terhadap perilaku personal hygiene saat menstruasi remaja putri SMP N 1 Gamping Sleman. Hasil penelitian ini sejalan dengan penelitian yang dilakukan oleh penelitian sebelumnya menunjukaan danya hubungan sumber informasi dari ibu terhadap prilaku personal hygiene dengan $p$ value $0,002<0,05$ (Sulistyaningrum, 2014). Berbeda dengan penelitian sebelumnya menunjukan hasil tidak terdapat hubungan antara dukungan guru terhadap personal hygiene saat mensturasi pada remaja putri dengan nilai $p$ value 0,998>0,05 (Yusuf \& Budiono, 2016). 
Rermaja putri perlu diberikan informasi yang baik dan positif melalui guru sekolah. Guru merupakan penyalur atau pemberi informasi pertama yang dilakukan disekolah setelah orangtua. Sehingga guru dapat memberikan informasi tentang sikap, pengetahuan dan praktik vulva hygiene, untuk memperhatikan kebersihan diri (vulva hygiene) pada remaja putri, sehingga siswa yang sudah terpapar informasi tersebut akan berdampak postif terhadap prilakunya (Rahman \& Rofika, 2014).

\section{Sumber Informasi dari Media Masa}

Berdasarkan hasil analisis terdapat hubungan antara sumber informasi dari media masa terhadap perilaku personal hygiene saat menstruasi remaja putri SMP N 1 Gamping Sleman. Hasil penelitian ini sesuai dengan penelitian yang dilakukan oleh penelitian sebelunya yang menunjukkan adanya hubungan antara informasi dari media dengan perilaku personal hygiene saat menturasi dengan nilai $p$ value 0,012 (Lestariningsih, 2015). Hasil penelitian ini didukung oleh penelitian yang dilakukan oleh peneliti sebelumnya yang menunjukan adanya hubungan antara terpapar iklan di media dengan perilaku personal hygiene saat menturasi (Fissehea, dkk, 2017). Media massa saat ini terbuka untuk mengangkat masalah kesehatan reproduksi termasuk didalamnya tentang higiene menstruasi. Iklan-iklan yang berkaitan dengan menstruasi, baik iklan tentang pembalut wanita ataupun obatobatan yang berkaitan dengan masalahmasalah gangguan haid banyak ditayangkan oleh media massa, baik elektronik maupun cetak Arifin dalam (Lestariningsih, 2015).

\section{Sumber Informasi dari Saudara Perempuan \\ Berdasarkan hasil analisis terdapat} hubungan antara sumber informasi dari saudara perempuan terhadap perilaku personal hygiene saat menstruasi remaja putri SMP N 1 Gamping Sleman. Hasil penelitian ini tidak sejalan dengan penelitian sebelumnya menunjukan hasil penelitian tidak terdapat hubungan sumber informasi dari kakak perempuan dengan praktik kebersih personal hygiene saat mensturasi dengan nilai $\mathrm{p}$ value $0,043>0,05$ (Purwanti, 2017). Berdasarkan informasi data primer yang didapatkan dalam penelitiannya menunjukkan informasi dari kakak perempuan menjadi faktor risiko peraktik kebersihan saat mensturasi yang buruk. Pemberi sumber informasi harus memiliki pengetahuan yang memadai tentang personal hygiene, sehingga pengetahuan yang dapat diberikan kepada remaja tentang menstruasi pertama berupa pengetahuan tentang proses terjadinya menstruasi secara biologis, dukungan emosional, dan dukungan psikologis. Keluarga atau saudara sebagai lingkungan utama remaja memegang peranan penting dalam membentuk perilaku remaja (Tarwoto \& Wartonah, 2010).

\section{Sumber Informasi dari Teman Sebaya}

Berdasarkan hasil analisis terdapat hubungan antara sumber informasi dari teman sebaya terhadap perilaku personal hygiene saat menstruasi remaja putri SMP N 1 Gamping Sleman. Hasil penelitian ini sama dengan penelitian yang dilakukan oleh penelitian sebelumnya menunjukkan terdapat hubungan antara dukungan sosial temana sebaya dengan praktik menstrual hygiene dengan nilai $p$ value $0,003<0,05$ (Auemaneekul, 2014). Pengaruh teman sebaya besar sekali terhadap perilaku individu. Perkembagan kehidupan sosial remaja ditandai dengan meningkatnya pengaruh teman sebaya. Remaja lebih banyak menghabiskan waktunya untuk berinteraksi sosial dengan teman sebayanya.Teman sebaya memberikan pengaruh yang besar terhadap sikap, minat, penampilan dan perilaku remaja. Hal tersebut dikarenakan komunikasi diantara teman sebaya lebih mudah dicerna dan diterima daripada komunikasi dengan orang tua atau yang lebih dewasa dari pada remaja (Desmita, 2012).

\section{Sumber Informasi dari Tenaga Kesehatan}

Berdasarkan hasil analisis terdapat hubungan antara sumber informasi dari orangtu terhadap perilaku personal hygiene saat menstruasi remaja putri SMP N 1 Gamping Sleman. Hasil penelitian ini sesui 
AuliaAnjan : Hubungan Sumber Informasi Dengan Perilaku Personal Hygiene Pada Remaja Putri Saat Menstruasi

dengan penelitian sebelumnya yang menunjukkan terdapat pengaruh setelah diberikan pendidikan kesehtan oleh tenaga kesehatan terhadap sikap dan perilaku personal hygiene saat mensturasi dengan nilai $p$ value $0,001<0,05$ (Meinarisa, 2019). Sumber informasi yang diberikan oleh tenaga kesehatan adalah upaya untuk meningkatkan pengetahuan kesehatan perorangan paling sedikit mengenai pengelolaan faktor risiko penyakit dan perilaku hidup bersih dan sehat dalam upaya meningkatkan status kesehatan, mencegah timbulnya penyakit dan memulihkan penyakit. Sumber infomasi dari tenaga kesehtan terkait dengan perilaku personal hygiene sangat penting agar dapat meningkatan pengetahuan remaja, terutama bagi remaja putri yang baru mendapatkan menstruasi, karena pengalaman baru yang mereka jalani sebagai perempuan seutuhnya. Selain itu, mendapatkan informasi dari tenaga kesehatan tentang kebersihan saat mensturasi merupakan bagian vital pendidikan kesehtan, sehingga akan terus berperilaku menjaga kebersihan saat mensturasi sampai usia dewasa bahkan sampai menoupose (Samsori, dkk, 2016).

\section{KESIMPULAN}

Implikasi

Sumber informasi tentang personal hygiene saat mensturasi remaja putri SMP N 1 Gamping diperoleh dari orangtua $(69,4 \%)$, guru sekolah $(43,5 \%)$, media sosial $(46,8 \%)$, saudara perempuan $(27,4 \%)$, teman sebaya $(22,6 \%)$ dan tenaga kesehatan (79\%). Sebagian besar siswi remaja putri SMP N 1 Gamping melakukan perilaku positif saat mensturasi $(62,9 \%)$. Terdapat hubungan yang signifikan antara sumber informasi terhadap perilaku personal hygiene saat menstruasi remaja putrid SMP N 1 Gamping Sleman.

\section{Keterbatasan}

Penelitian ini merupakan penelitian kuantitatif yang datanya diambil dari hasil pengisian kuesioner oleh responden, untuk itu perlu dilakukan pendalaman pada jenis informasi yang diperoleh dengan cara pendekatan kualitatif.

\section{DAFTAR PUSTAKA}

Auemaneekul, Naruemon. (2014). Menstrual Hygiene Practies among Adolescents in a Rural District of Nepal. Asia Journal of Public Health. (4): 8-15.

Allaily. (2016). Gambaran Tingkat Pengetahuan Remaja Tentang Kebersihan Organ Genitalia Eksterna Di SMAN 90 Jakarta. Skripsi Diterbitkan. Jakarta: Universitas Islam Negeri Syarif Hidayatullah.

Andira, D. (2010). Seluk Beluk Kesehatan Reproduksi Wanita. Yogyakarta : A PLUS BOOKS.

Desmita. 2012. Psikologi Perkembangan Peserta Didik. Bandung: Rosda Karya.

Djannah, N, S \& Gustina, E. (2015). Sumber Informasi Dan Pengetahuan Tentang Menstrual Hygiene Pada Remaja Putri. JurnaL Kesehatan Masyarakat. Vol 10. No 2. 147-152.

Eswi,A., Helal, H., Elarousy, W. 2014. Menstrual Attitude and Knowledge among Egyptian Female Adolescents. Journal of American Science, 8(6).

Fissehea, M. A.,Yigzaw, K.,Hadija, Y. Y. 2017. Menstrual hygiene practice and associated factors among secondary school girls in wagera district, northwest; ethiqpia; a cross-sectional study.

Irianto, K. (2015). Kesehatan Reproduksi (Reproductive Health) Teori dan Praktikum. Bandung : ALFABETA.

Kemenetrian Kesehatan Republik Indonesia. (2017). Data dan Informasi Profil Kesehatan Indonesia Tahun 2016.

Lestariningsih, S. (2015). Faktor-Faktor Yang Berhubungan Dengan Praktik Higiene Menstruasi.

Meinarisa. (2019). Pengaruh Pendidikan Kesehatan Menstrual Hygiene (PMH) Terhadap Sikap Remaja Putri dalam Menjaga Kebersihan Diri Selama Menstruasi.

Nugroho, S, F., Wijayanti, C, A \& Lufiati, E, D. (2015). Faktor-Faktor Yang Berhubungan Dengan Perilaku Personal Hygiene Organ Genetalia Pada Pelajar Putri Di SMKN 7 Surakarta. Artikel Penelitian. 
AuliaAnjan : Hubungan Sumber Informasi Dengan Perilaku Personal Hygiene Pada Remaja Putri Saat Menstruasi

Notoatmodjo, S. (2014). Metedologi Penelitian Kesehatan. Jakarta : PT. Rineka Cipta.

Purwanti, S. 2017. Praktik Kebersihan Saat Mensturasi Remaja Di Kabupaten Pati Tahun 2017.

Rahman, \& Rofika W, (2014).Pengaruh Sikap, Pengetahuan dan Praktik vulvaHygiene dengan Kejadian Keputihan pada Remaja Putri di SMPN 01 Mayong Jepara. Jurnal Keperawatan Maternitas, 2(2): 117126.

Sulistyoningrum, R. (2014). Hubungan antara Dukungan Sosial dan Akses Terhadap Informasi dengan Perilaku Sehat Reproduksi Remaja Slow Learner. Jurnal Promosi Kesehatan, $1(1): 18-24$.

Suhasni, K.,Chandra, M. (2016). Factor Inflencing Menstural Hygiene Practice Among Late Adolescent Girls in an Perkotaan Belgaum.

Somsri, P., Satheannoppakao, W., Tipayamongkholgul, M., \& Vatanasomboon, P. 2016. Research Article A Cosmetic Content - Based Nutrition Education Program Improves Fruit and Vegetable Consumption Among Grade 11 Thai Students. Journal of Nutrition Education and Behavior, 48(3), 190198.e1.

Tarwoto \& Wartonah. (2010). Kesehatan Reproduksi Remaja dan Wanita. Jakarta : Salemba Medika.

Yusuf, D.F.,Budiono, I. 2016. Faktor Yang Berhubungan Dengan Praktik Menstrual Hygiene Genitalia Pada Siswi Smplb Tunagrahita.

Word Health Organization (WHO). (2018). Child and adolescent health and development. 